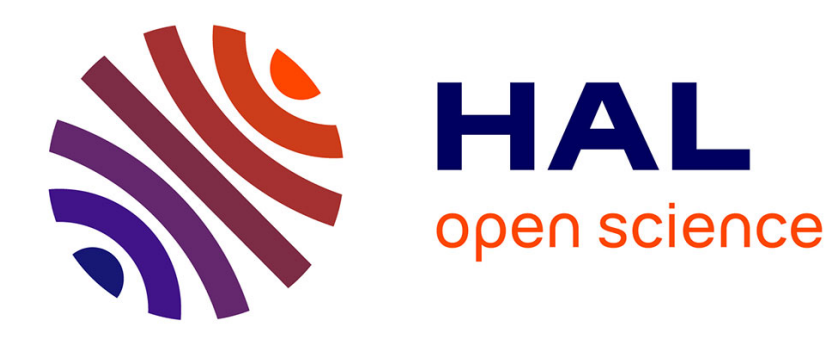

\title{
Optimal Control of Interbank Contagion Under Complete Information
}

\author{
Andreea Minca, Agnès Sulem
}

\section{To cite this version:}

Andreea Minca, Agnès Sulem. Optimal Control of Interbank Contagion Under Complete Information. Statistics \& Risk Modeling with Applications in Finance and Insurance, 2014, 31 (1), pp.1001-1026. 10.1524/Strm.2014.5005 . hal-00916695v2

\section{HAL Id: hal-00916695 https://hal.inria.fr/hal-00916695v2}

Submitted on 29 Jan 2014

HAL is a multi-disciplinary open access archive for the deposit and dissemination of scientific research documents, whether they are published or not. The documents may come from teaching and research institutions in France or abroad, or from public or private research centers.
L'archive ouverte pluridisciplinaire HAL, est destinée au dépôt et à la diffusion de documents scientifiques de niveau recherche, publiés ou non, émanant des établissements d'enseignement et de recherche français ou étrangers, des laboratoires publics ou privés. 


\title{
Optimal Control of Interbank Contagion under Complete Information
}

\author{
Andreea Minca*, Agnès Sulem ${ }^{\dagger}$
}

December 28, 2013

\begin{abstract}
We study a preferred equity infusion government program set to mitigate interbank contagion. Financial institutions are prone to insolvency risk channeled through the network of interbank debt and to the risk of bank runs. The government seeks to maximize, under budget constraints, the total net worth of the financial system or, equivalently, to minimize the dead-weight losses induced by bank runs. The government is assumed to have complete information on interbank debt. The problem of quantifying the optimal amount of infusions can be expressed as a convex combinatorial optimization problem, tractable when the set of banks eligible for intervention (core banks) is sufficiently, yet realistically, small. We find that no bank has an incentive to withdraw from the program, when the preferred dividend rate paid to the government is equal to the government's outside return on the intervention budget. On the other hand, it may be optimal for the government to make infusions in a strict subset of core banks.

Keywords: Systemic risk, Liquidity risk, Bank runs, Financial contagion, Financial Networks, Optimal Intervention, Bail-outs.
\end{abstract}

${ }^{*}$ School of Operations Research and Information Engineering, Cornell University, Ithaca, NY 14850, USA, email: acm299@cornell.edu

${ }^{\dagger}$ INRIA Paris-Rocquencourt, Domaine de Voluceau, Rocquencourt, BP 105, Le Chesnay Cedex, 78153, France, and Université Paris-Est, F-77455, Marne-la-Vallée, France, email: agnes.sulem@inria.fr 


\section{Introduction}

During the recent financial crisis, systemic risk has emerged as a major concern for governments, financial regulators and risk managers. By contrast with the traditional approach in risk management, the focus is no longer on modeling and managing the risks faced by a single financial institution, but on taking into account the interrelations between financial institutions and the complex mechanisms of distress propagation.

Limiting systemic risk requires building new analytical and computational tools for macro-prudential regulation. Most research in this area focuses on the important topic of systemic risk measurement and attribution. Giesecke and Kim (2011) propose such measures within the framework of reduced form models (in reduced form models, the ensemble of firms in the economy is represented as a portfolio in which failures arrive according to some exogenous process). Some works propose systemic risk measures within the framework of network models for insolvency risk in banking systems, see e.g. Lehar (2005), Amini et al. (2013a), Cont et al. (2012). Blanchet and Shi (2012) extend the application field of the network framework to insurance-reinsurance markets. Chen et al. (2012) propose an axiomatic approach to systemic risk measures.

Network models for systemic risk have the advantage of being both structural (they integrate explicitly the details of banks balance sheets and the interbank debt) and tractable. Such features are required for quantifying best regulatory responses to systemic crisis. A recent example in this sense is Rogers and Veraart (2012), who use networks as decision tools for the establishment of rescue consortia.

Our contribution is within the area of systemic risk management. We use network models to investigate a government's problem of optimal intervention in the form of preferred equity infusions, i.e, the government earns a preferred fixed dividend on its share of the banks' capital. This problem is motivated by the government interventions during the recent crisis, which took forms of recapitalizations, see e.g. Swagel (2009), Veronesi and Zingales (2010). The rationale and the gain from these equity infusion programs is an important topic of notable research in the finance literature, both empirical and theoretical, see Philippon and Skreta (2010), Veronesi and Zingales (2010), Bayazitova and Shivdasani (2012), Philippon and Schnabl (2009).

Several possible reasons for equity infusion programs have been advanced in this literature (see Veronesi and Zingales (2010)). One theory is that the government recapitalized a banking sector that restricted lending because of debt overhang. The resulting optimization program is investigated in Philippon and Schnabl (2009). The second possible reason is that government intervened in order to avoid runs by short term creditors, since runs destroy value and are inefficient. Runs by short term creditors played a central role during 
the crisis, see Gorton and Metrick (2012). In this paper we investigate this rationale.

Some of the questions we ask are: Is an equity infusion program such as the British equity infusion program or the US CPP (Capital Purchase Program) of 2008 justified when we take into account the runs of short term creditors? Would it be preferable for the government to invest directly in the economy than invest in the banks' equity? How to optimally inject equity in each bank? Is the intervention budget constraint saturated at the optimal solution? ?1

To answer these questions, we build a model in which banks use a combination of short term debt and interbank debt to invest in an illiquid asset and a risk-free asset ("cash"). The banks are exposed to two interdependent sources of risk. First, they are exposed to insolvency risk channeled through the network of interbank debt. Second, they are exposed to funding liquidity risk due to the possibility of runs by external short term creditors (e.g., money market funds). In case a bank suffers a short term creditor outflow, it is forced to prematurely liquidate part of the illiquid asset realizing a value below the fundamental value of this asset. This creates dead-weight losses in the system.

Insolvency risk and funding liquidity risk are interdependent. The underlying network of interbank debt transmits losses among financial institutions, which then see their capital depleted and consequently may face withdrawals in the funding provided to them by short term creditors. If the withdrawals are severe (bank run) then the dead-weight losses may be so large that the bank becomes insolvent. Insolvency entails complete liquidation and, due to the dead weight losses, prompts writedowns and capital depletion to the counterparties. This leads to large feedback effects. The feature that dead-weight losses may drive firms into insolvency which largely drives these feedback effects, is discussed in the economics literature in Diamond and Rajan (2011). This is a new feature that this model adds to quantitative network-based contagion literature.

We set up an optimal preferred equity infusion program by a government with constrained budget who aims at maximizing the total net worth of the financial system. The financial system we consider is comprised by the banks, their external debt holders and the government who is a preferred equity investor in the banks. The key ingredient is the fact that this total net worth accounts for dead-weight losses induced by bank runs. Equally important, the government values the illiquid asset at its fundamental value, thereby taking a long-term perspective on this asset.

We capture the government's tradeoff between investing in the banks equity and directly funding projects in the economy by introducing an outside return rate for the government's investment. This creates an opportunity cost present in the government's optimization

\footnotetext{
${ }^{1}$ In the US, the intervention budget is imposed to the government by Congress vote, and therefore it is important to determine in a quantitative model whether this constraint is saturated.
} 
criterion.

The government problem is set under full information, by which we mean that the controller (the government) observes the entire interbank debt network. The corresponding problem under partial information is treated in the companion paper Amini et al. (2012). We also consider that only an exogenously chosen set of banks are eligible to receive government equity infusions. Indeed, the network of financial institutions contains banks, mutual funds, hedge funds, etc. and it is reasonable to assume that not all financial institutions are eligible for equity infusions. We will call the subset of institutions that are eligible to receive such equity infusions core banks. They can be specified using an exogenous rule, e.g., the top US banks in terms of assets.

Our analysis (Theorem 16) shows that under the considered optimization program, all banks achieve a higher capital with intervention than without intervention after the preferred dividend of the government is detached. This means that banks are better off by receiving the equity infusion and paying the dividend and no bank can gain by withdrawing from the program. This is consistent with our model setting in which the decision of the government cannot be refused by the banks $2^{2}$.

The increase in the net worth of the financial system is due the mitigation of deadweight losses and to a pooling of losses that occurs into the system. The intuition behind the pooling of losses is as follows. The banks that are solvent, yet would have become illiquid absent the intervention, are forced to transfer funds to the government in the form of the preferred dividend. The bigger their holdings in illiquid asset funded by unstable short term debt, the bigger the equity infusion they receive and the larger the dividend. These funds are used to absorb losses stemming from banks that become insolvent and thus mitigate the amount of losses that eventually reach the taxpayer.

We show that under the proposed optimization program, the government does not make equity infusions if the system is not prone to dead-weight losses induced by bank runs (Proposition 7). Our results offer a methodology to test the theory that the US equity infusion was set up to avoid bank runs. The fact that a government may find it optimal to make equity infusions to avoid banks runs does not necessarily create moral hazard and incentives for banks to expose themselves to bank runs. Indeed, if the dividend is sufficiently large, banks that are fundamentally solvent in absence of bank runs and that receive equity infusions to avoid bank runs are effectively forced to participate with the government in the pooling of losses. Since the equity infusion is larger when the bank has both a large amount

\footnotetext{
${ }^{2}$ During the 2008 crisis, amid the Capital Purchase Program, the US banks that received equity infusions did not have the option to refuse the government decision, see e.g. Veronesi and Zingales (2010), Landler and Dash (2008). The Capital Assistance Program (CAP) replaced the Capital Purchase Program in 2009, offering participating banks redemption options. CAP securities valuation is investigated in Glasserman and Wang (2011).
} 
of illiquid asset and a large fraction of unstable short term debt to total debt, it is in this case precisely that the bank will have to pay a larger dividend.

Our main result (Theorem 8) shows that the optimal equity infusion problem becomes a convex optimization problem with a combinatorial aspect. The combinatorial aspect of the optimization problem becomes relevant when the continuum of losses of the paper by Eisenberg and Noe (2001) is lost. This continuum is lost as soon as there are fixed and important bankruptcy costs, see e.g. Rogers and Veraart (2012), Amini et al. (2013a). This aspect is highly relevant to systemic crisis which have an illiquidity component (such as the crisis of $2007-2009)$.

Specifically, for each subset of core banks, we can compute the optimal solution when we restrict intervention to that specific set. We then optimize over all such possible subsets of core banks. The solution to this problem gives for each banks the optimal amount of equity infusions.

Several insights come from our results. First, it may be optimal to make non-trivial equity infusions when the system is prone to dead-weight losses induced by bank runs. Since the government's criterion accounts for its return on the direct investment into the economy, non-trivial infusions imply that it is preferable to increase the risk bearing capacity of the financial system by avoiding premature asset liquidations. Second, it may not be optimal to make equity infusions in all core banks. Third, there exists a maximum budget beyond which the marginal cost from intervention surpasses its marginal gain. As a consequence, beyond a certain point, the budget constraint will not be saturated. This result indicates that if the government would make equity infusions beyond a certain limit, it would, in effect, transfer the losses from the existing creditors and shareholders of failed banks to the taxpayer.

Our paper is organized as follows. In the next section we present a model for distress propagation in a network of financial institutions that are prone both to insolvency risk and to bank runs. In Section 2.3 we introduce the fixed point equation that determines the equilibrium asset-to-debt ratio for all banks and the equilibrium dead-weight losses. In Section 3 we show that the government optimization problem can be stated as a convex combinatorial optimization problem. In Section 3.3 we perform numerical experiments. The paper finishes with a technical appendix.

\section{The model}

We consider a one period network model for the cross-section of a financial system, $t=$ 0,1 . The financial system is constituted of a set $[n]:=\{1, \ldots, n\}$ of interrelated financial institutions ("Banks") and a continuum of outside creditors. There exists a government 
that makes instantaneous equity infusions in the form of cash at time 0 .

At time 0, banks come with capital, they have debt to each other which matures at time 1 (long-term debt) and they have short-term debt to the continuum of outside creditors. The debt to the outside creditors is of two types, stable, i.e., it is not withdrawn at time 0 , or unstable, i.e., the outside creditors may decide to withdraw funding, depending on the state of the financial system and the financial health of the bank in question.

On the asset side, bank hold investments in cash and an illiquid asset. The illiquid asset matures at time 1 and has a fundamental price normalized at 1 at time 0 . However, if the asset needs to be prematurely liquidated at time 0 , it is then valued at a fire-sale price $0<p \leq 1$. The price of the asset at time 1 is unknown at time 0 and market participants may have different beliefs about a fundamental shock that may change the fundamental value of the illiquid asset from time 0 to time 1 . The government expects that the price of the illiquid asset will be 1 at time 1, i.e., the government does not expect a shock in the fundamental value of the illiquid asset between times 0 and 1 . This can be interpreted as the government being an investor less jittery about the valuation of the illiquid asset than the short term creditors. We do not model directly the beliefs of the outside creditors, but we assume an exogenous short term creditor outflow schedule that incorporates these beliefs.

We are interested in the equilibrium reached at time 0.

\subsection{Market participants and their interrelations}

We now describe the financial system at time 0 .

Debt. For a bank $i \in[n], \ell_{i}$ denotes the sum of its long term debt and stable short term debt and $s_{i}$ its unstable short term debt. A proportion $\pi_{i j}$ of the debt $\ell_{i}$ is toward

bank $j$, with $\sum_{j \in[n]} \pi_{i j} \leq 1$. The remaining fraction $1-\sum_{j \in[n]} \pi_{i j}$ of $\ell_{i}$ gives the proportion of stable short term debt.

Assets. We let $\gamma_{i}$ and $y_{i}$ denote the holdings in cash and respectively the holdings in illiquid asset of bank $i$. One bank's interbank debt is another bank's interbank asset. The total value of the interbank assets of $i$ is therefore given by $\sum_{j \in[n]} \ell_{j} \pi_{j i}$.

The capital of a bank is given by the value of its assets minus the value of its debt. A bank is said to be solvent if the value of its assets is larger than the value of its debt, i.e., if its capital is positive. Alternatively, the solvency condition can be expressed in terms of the the asset-to-debt ratio which must be greater than one. The capital and asset-todebt ratio determined under the assumption that no debtor banks are insolvent are called fundamental capital and asset-to-debt ratio. 
The fundamental capital of bank $i$ at time 0 is given by

$$
c_{i}:=y_{i}+\gamma_{i}+\sum_{j \in[n]} \ell_{j} \pi_{j i}-\ell_{i}-s_{i}
$$

The fundamental asset-to-debt ratio of bank $i$ at time 0 is given by

$$
\begin{aligned}
r_{i} & :=\frac{y_{i}+\gamma_{i}+\sum_{j \in[n]} \ell_{j} \pi_{j i}}{\ell_{i}+s_{i}} \\
& =1+\frac{c_{i}}{\ell_{i}+s_{i}} .
\end{aligned}
$$

The fundamental solvency condition for a bank $i$ can be expressed in term of the fundamental asset-to-debt ratio as $r_{i} \geq 1$.

Clearly, if there exists a bank that is insolvent, then its creditors cannot account the full value of their interbank assets and their asset-to debt ratio is no longer determined as above. The equilibrium asset-to-debt ratios for all banks will be determined from a fixed point equation, as we show in the next section.

\subsection{Financial contagion}

If $r_{i}<1$ bank $i$ is fundamentally insolvent and all holdings of the illiquid asset are sold at the fire-sale price $p \leq 1$. The proceeds are distributed to creditors proportionally to the outstanding debt as in Eisenberg and Noe (2001). The creditors of an insolvent bank will suffer a loss and, in turn, may become insolvent themselves.

Importantly, even if a bank is fundamentally solvent, i.e. $r_{i} \geq 1$, it may be forced to liquidate some of its illiquid asset holdings due to the outflow of short term creditors. We model the short term creditor outflow schedule by an exogenous function $g(\cdot):[1, \infty) \rightarrow[0,1]$ of the asset-to-debt ratio, on which we make the following assumption.

Assumption 1. The short term creditor outflow schedule $g$ has the following properties:

(i) There exists $\bar{r} \geq 1$ such that $g(x)=0$, for $x \geq \bar{r}$;

(ii) $x \longmapsto g(x)$ is non-increasing, twice differentiable and convex;

(iii) $g^{\prime} \geq-1$.

The first condition ensures that for sufficiently large asset-to-debt ratios there are no short term creditor outflows. The second condition states that the creditor outflow is decreasing with the asset-to-debt ratio. This assumption is reasonable, since banks with higher asset-to-debt ratios have lower future insolvency risk. The convexity assumption 
can be interpreted as an increase in the outflow rate as we approach the insolvency level (asset-to-debt ratio equal to 1 ). The last assumption is a tractability assumption that puts a lower bound on the withdrawal rate.

Importantly, the short term creditor outflow schedule is assumed to incorporate all the beliefs of the short-term creditors about the fundamental value of the illiquid asset at its maturity date 13

As a consequence of the short-term creditors behavior, captured by the short term creditor outflow schedule, a bank whose asset-to-debt ratio falls below $\bar{r}$ may be forced to liquidate part of its illiquid asset holdings at the fire-sale price $p$.

Consider now a bank with asset-to-debt ratio $x$, total short-term debt $s$, cash holdings $\gamma$ and illiquid asset holdings $y$. The short term creditors will claim back an amount $s g(x)$ of the short term debt. If the cash available to the bank cannot cover the amount $s g(x)$, then the bank will have to liquidate a quantity $\frac{(\gamma-s g(x))^{-}}{p} \wedge y$ of the illiquid asset. In doing so, the bank will effectively have a loss in its' asset value, since the liquidated value will achieve a price $p \leq 1$ instead of its fundamental price 1 . The total loss on the asset side in this case is $\left(\frac{(\gamma-s g(x))^{-}}{p} \wedge y_{i}\right)(1-p)$.

In our model, an insolvent bank is completely liquidated and its entire illiquid asset holdings are valued at the fire-sale price $p$ and not at the fundamental value 1 . In this case there will be a loss on the asset side equal to $y(1-p)$.

The losses arising on the asset side as a result of liquidations are called dead-weight losses and are defined as follows.

Definition 1. We define the dead-weight loss of a bank with asset-to-debt ratio $x$, total short-term debt $s$, cash holdings $\gamma$ and illiquid asset holdings y as follows

$$
\delta(x, s, \gamma, y):= \begin{cases}\left(\frac{(\gamma-s g(x))^{-}}{p} \wedge y\right)(1-p) & \text { if } x \geq 1 \\ y(1-p) & \text { if } x<1 .\end{cases}
$$

If $g \equiv 0$, dead-weight losses occur only when firms become insolvent. This is like in Rogers and Veraart (2012), where there are fixed liquidation costs when firms become insolvent.

If $g>0$, dead-weight losses can occur due to withdrawal of short term creditors (part of the illiquid asset is de facto valued at the fire-sale price $p$ ). Unlike Rogers and Veraart (2012), these dead-weight losses may occur even if all banks are solvent.

\footnotetext{
${ }^{3}$ Modeling the roll-over coordination game of the short term creditors is beyond the scope of this paper, and thus the short term creditor outflow schedule is exogenous. For models of insolvency and rollover risk we refer the reader to Morris and Shin (2009), Lütkebohmert et al. (2012), He and Xiong (2012), Krishenik et al. (2012).
} 
Note that the dead-weight losses will decrease the asset-to-debt ratio of the bank, which will entail a larger short-term creator outflow and consequently more liquidations. It is possible that the asset-to-debt ratio reaches 1 as a result of this process, at which point the bank is insolvent. If $p<1$ then the dead-weight loss has a jump when the asset-to-debt ratio reaches 1 , since all the illiquid asset is then sold.

A bank $i$ with asset-to-debt ratio $x_{i}<1$, i.e. a bank that is insolvent, will generate a loss on the asset side of its creditors, irrespective how it has reached insolvency. The creditors will then receive a percentage $x_{i}<1$ of their debt, and thus contagion ensues. Note in particular that for an insolvent bank, under the proportionality assumption, the asset-to-debt ratio represent the recovery rate of the creditors.

\subsection{Equilibrium with government intervention}

We consider now that there exists a government that makes instantaneous equity infusions in the form of cash at time 0 . We assume that only a subset $\mathcal{C} \subseteq[n]$ are eligible for intervention. This set represents the set of core banks in the financial system and are specified by an exogenous rule.

The intervention budget of the government is $M$. The government injects preferred equity $\xi_{i} \in[0, M]$ in bank $i \in[n]$, with $\xi_{i}=0$ for $i \in[n] \backslash \mathcal{C}$. After the (instantaneous) intervention, a bank $i \in[n]$ holds $\gamma_{i}+\xi_{i}$ of cash. The investment pays to the government $a$ preferred dividend rate $d$ at time 1 . The equilibrium values of the asset-to-debt ratios of all banks in the system are jointly given by the fixed point of the following function, similar as in Eisenberg and Noe (2001), Cifuentes et al. (2005), Amini et al. (2013b),

$$
\Phi(R(\xi), \xi)=R(\xi)
$$

of the non-linear map $\Phi$ on $[0, \infty)^{n} \times[0, \infty)^{n}$

$$
\Phi(x, \xi)_{i}:=\frac{y_{i}-\delta\left(x_{i}, s_{i}, \gamma_{i}+\xi_{i}, y_{i}\right)+\gamma_{i}+\xi_{i}+\sum_{j \in[n]} \ell_{j} \pi_{j i}\left(x_{j} \wedge 1\right)}{\ell_{i}+s_{i}}
$$

Remark 2. Note that the dead-weight loss $0 \leq \delta(\cdot, \cdot, \cdot, y) \leq y(1-p)$. Consequently, for $(x, \xi) \in[0, \infty)^{n} \times[0, \infty)^{n}$ and $i=1, \ldots, n$, we have that

$$
0 \leq \frac{p y_{i}+\gamma_{i}+\xi_{i}+\sum_{j \in[n]} \ell_{j} \pi_{j i}}{\ell_{i}+s_{i}} \leq \Phi(x, \xi)_{i} \leq \frac{y_{i}+\gamma_{i}+\xi_{i}+\sum_{j \in[n]} \ell_{j} \pi_{j i}}{\ell_{i}+s_{i}} .
$$

The difference between the above map and the baseline specification in Eisenberg and Noe (2001) is that only a fraction of the illiquid asset is valued at its fundamental price. 
The liquidated quantity is evaluated at the fire-sale price. This means that, in equilibrium, there is a dependence between the value of the assets and the value and the stability of the debt. This dependence is induced by the behavior of the short term creditors captured by the short term creditor outflow schedule $g$ and the network of interbank debt. Of course, if $p=1$, then the equilibrium dead-weight losses are equal to zero and the fixed point of the map $\Phi$ is the same as in Eisenberg and Noe (2001). In this case, the short term creditor behavior does not matter.

We have the following lemma.

Lemma 3. For each $\xi \in[0, \infty)^{n}$, the function $x \rightarrow \Phi(x, \xi)$ is monotone and bounded. Moreover, there exists a largest fixed point for this function.

The following proof mimics that of Rogers and Veraart (2012).

Proof. Fix $\xi \geq 0$. Since the dead-weight loss $x \rightarrow \delta$ is a non-increasing function of $x$, we immediately have from Eq. (3) that for all $i=1, \ldots, n, x \rightarrow \Phi(x, \xi)_{i}$ is a non-decreasing function of $x$. By Remark 2, the map $\Phi$ is bounded.

We now define recursively the following sequence, using the upper bound of the map $\Phi$ : For all $i=1, \ldots, n$, we let $q_{i}^{0}:=\frac{y_{i}+\gamma_{i}+\xi_{i}+\sum_{j \in[n]} \ell_{j} \pi_{j i}}{\ell_{i}+s_{i}}$. We let $q^{n+1}:=\Phi\left(q^{n}, \xi\right)$. By the monotonicity of the map $x \rightarrow \Phi(x, \xi)_{i}$, we have $q^{n+1} \leq q^{n}$. Since $q^{n}$ are non-negative, there exists a monotone limit $q^{*}:=\downarrow \lim _{n \rightarrow \infty} q^{n}$. Since $x \rightarrow \Phi(x, \xi)$ is continuous from above, it follows that $q^{*}$ is a fixed point. Since any fixed point is bounded from above by $\frac{y_{i}+\gamma_{i}+\xi_{i}+\sum_{j \in[n]} \ell_{j} \pi_{j i}}{\ell_{i}+s_{i}}$ it follows from the monotonicity of $\Phi$ that any fixed point of the map $\Phi$ is bounded from above by $q^{*}$, i.e., $q^{*}$ is the largest fixed point. This concludes the proof.

Lemma 3 proves the existence of a largest equilibrium asset-to-debt ratio. In the sequel we consider the largest fixed point of the map $\Phi$.

The equilibrium dead-weight losses of bank $i$ are given by

$$
\Delta_{i}(\xi):=\delta\left(R_{i}(\xi), s_{i}, \gamma_{i}+\xi_{i}, y_{i}\right)
$$

The equilibrium capital of bank $i$, including the government share, is $\left(R_{i}(\xi)-1\right)\left(\ell_{i}+s_{i}\right)$. The face value of the government share is $\xi_{i}(1+d)$. The government investment is in the form of preferred equity, i.e., it absorbs losses after the ordinary shareholders and before the outside debt holders.

It follows that the equilibrium value of the government investment in bank $i$ is

$$
\begin{aligned}
\left(R_{i}(\xi)-1\right)^{+}\left(\ell_{i}+s_{i}\right) & \wedge \xi_{i}(1+d) \\
& =\xi_{i}(1+d)-\left(\left(R_{i}(\xi)-1\right)^{+}\left(\ell_{i}+s_{i}\right)-\xi_{i}(1+d)\right)^{-}
\end{aligned}
$$


The equilibrium capital of bank $i$, net of the face value of the government share, is then given by

$$
\begin{aligned}
C_{i}(\xi) & :=\left(R_{i}(\xi)-1\right)\left(\ell_{i}+s_{i}\right)-\xi_{i}(1+d) \\
& =y_{i}+\gamma_{i}+\sum_{j \in[n]} \ell_{j} \pi_{j i}\left(R_{j}(\xi) \wedge 1\right)-\Delta_{i}(\xi)-\left(s_{i}+\ell_{i}\right)-\xi_{i} d
\end{aligned}
$$

The equilibrium capital in absence of government intervention is given by

$$
C_{i}(0)=y_{i} P+\gamma_{i}+\sum_{j \in[n]} \ell_{j} \pi_{j i}\left(R_{j}(0) \wedge 1\right)-\Delta_{i}(0)-\left(s_{i}+\ell_{i}\right)
$$

We obtain thus the difference in the capital with and without intervention

$$
C_{i}(\xi)-C_{i}(0)=\left(\Delta_{i}(0)-\Delta_{i}(\xi)\right)+\sum_{j \in[n]} \ell_{j} \pi_{j i}\left(R_{j}(\xi) \wedge 1-R_{j}(0) \wedge 1\right)-\xi_{i} d
$$

The first two terms are positive.

We now compute the total value of the government investment. We assume that the part of the budget non invested in the banks bears a return rate to which we refer as outside return rate.

Remark 4. The outside return rate can be interpreted not as a risk free rate but as the return on investment that the government would have by directly funding projects in the economy.

Assumption 2. We assume that the outside return rate is equal to the dividend rate $d$ paid by the banks.

Since the problem setup gives the banks no option to refuse the government equity infusion, if the outside return rate were smaller that $d$, then the government would have an incentive to invest in a healthy bank in order to earn the preferred dividend. Also if the outside return rate were larger than $d$, then the government would provide capital "too cheaply" for the banks.

Using Eq. (4) and by the outside return rate $d$, we obtain the total value of the government investment

$$
M(1+d)-\sum_{i \in[n]}\left(\left(R_{i}(\xi)-1\right)^{+}\left(s_{i}+\ell_{i}\right)-\xi_{i}(1+d)\right)^{-} .
$$


The total value of the investment of the outside creditors is given by

$$
\sum_{i \in[n]}\left(R_{i}(\xi) \wedge 1\right)\left(s_{i}+\ell_{i}\left(1-\sum_{j \in[n]} \pi_{i j}\right)\right)
$$

\section{Government optimization problem}

\subsection{Problem statement}

The government has a constrained budget $M$ and its objective is to maximize the overall net worth of the financial system. Recall that the government assigns probability one to the illiquid asset having the same fundamental value 1 at time 1 . The net worth of the financial system (to the government) is thus deterministic and defined as the total equilibrium capital of the banks given in Eq. (5), plus the total value of the government investment as given in Eq. (8), plus the value of the outside creditors's investment given in Eq. (9).

The total net worth of the financial system is given by

$$
\begin{aligned}
V(\xi):= & \sum_{i \in[n]}\left(y_{i}+\gamma_{i}+\sum_{j \in[n]} \ell_{j} \pi_{j i}\left(R_{j}(\xi) \wedge 1\right)-\Delta_{i}(\xi)-\left(\ell_{i}+s_{i}\right)-\xi_{i} d\right) \\
& +\sum_{i \in[n]}\left(R_{i}(\xi) \wedge 1\right)\left(s_{i}+\ell_{i}\left(1-\sum_{j \in[n]} \pi_{i j}\right)\right) \\
& +M(1+d)-\sum_{i \in[n]}\left(\left(R_{i}(\xi)-1\right)^{+}\left(\ell_{i}+s_{i}\right)+\xi_{i}(1+d)\right)^{-} \\
= & \sum_{i \in[n]}\left(y_{i}+\gamma_{i}\right)+M(1+d) \\
& -\sum_{i \in[n]} \Delta_{i}(\xi)-\sum_{i \in[n]}\left(R_{i}(\xi)-1\right)^{-}\left(s_{i}+\ell_{i}\right) \\
& -\sum_{i \in[n]}\left(\xi_{i} d+\left(\left(R_{i}(\xi)-1\right)^{+}\left(\ell_{i}+s_{i}\right)-\xi_{i}(1+d)\right)^{-}\right) .
\end{aligned}
$$

Note that $\sum_{i \in[n]}\left(y_{i}+\gamma_{i}\right)+M(1+d)$ represents the fundamental net worth of the financial system (including the government intervention funds valued at the outside return rate). We can further write the total ex-post value in the system

$$
V(\xi)=\sum_{i \in[n]}\left(y_{i}+\gamma_{i}\right)+M(1+d)-L(\xi)
$$


where $L(\xi)$ represents the total loss in the financial system:

$$
\begin{aligned}
L(\xi):= & \sum_{i \in[n]} \Delta_{i}(\xi)+\sum_{i \in[n]}\left(R_{i}(\xi)-1\right)^{-}\left(s_{i}+\ell_{i}\right) \\
& +\sum_{i \in[n]} \xi_{i} d+\sum_{i \in[n]}\left(\left(R_{i}(\xi)-1\right)^{+}\left(\ell_{i}+s_{i}\right)+\xi_{i}(1+d)\right)^{-} .
\end{aligned}
$$

The total loss in the financial system has four components, that represent respectively the total dead-weight loss, the loss to the outside creditors, the opportunity cost of the government (who could have invested the intervention amount at the government's outside return rate) and the loss taken by the government on its investment in the banks. The government optimization problem will amount to minimizing this total loss.

We define the set of admissible intervention strategies as

$$
\mathcal{A}_{M}:=\left\{\xi \in \mathbb{R}_{+}^{n} \mid \forall i \in[n] \backslash \mathcal{C}, \xi_{i}=0 ; \sum_{i \in \mathcal{C}} \xi_{i} \leq M\right\} .
$$

We consider the following problem of optimal equity infusions with maximum budget $M$

$$
\underset{\xi \in \mathcal{A}_{M}}{\operatorname{aaximize}} V(\xi)
$$

or equivalently, using Eq. [11,

\section{Problem 5.}

$$
\mathcal{P}_{M}:=\underset{\xi \in \mathcal{A}_{M}}{\operatorname{Minimize}} L(\xi)
$$

We make the following assumption.

Assumption 3. If there are multiple solutions to the above problem, then the government prefers the one that maximizes the value of its investment in the banks as given in Eq. (8).

\subsection{Problem solution}

We begin by showing that the government never invests in an insolvent bank.

Proposition 6. Let $\xi^{*}$ a solution to the government optimization problem $\mathcal{P}_{M}$. Then, $R_{i}\left(\xi^{*}\right)<1$ implies that $\xi_{i}^{*}=0$. 
Proof. For any $i$ such that $R_{i}\left(\xi^{*}\right)<1$ we have that $\Delta_{i}\left(\xi^{*}\right)$ does not depend on $\xi_{i}^{*}$. If $\xi_{i}^{*}>0$ we would have a direct transfer from the government to the outside creditors which would not increase the value of the system.

The following proposition is without surprise and can be immediately checked. There are no interventions if the fire-sale price of the illiquid asset is the same as the fundamental price since in this case there are no dead-weight losses to reduce. Also, there are no intervention if all banks are initially solvent and liquid.

Proposition 7. If $r_{i} \geq 1$ and $\gamma_{i} \geq s_{i} g\left(r_{i}\right)$ for all $i \in[n]$ or if $p=1$, then there is no intervention, i.e., $\xi^{*} \equiv 0$ is the unique solution to $\mathcal{P}_{M}$.

We now give the first main result of the paper, Theorem 8 , in which we quantify the optimal intervention in the case with a fire-sale price below the fundamental value and when there is a bank that is fundamentally insolvent or illiquid.

In order to solve the optimal intervention problem, we split the problem and each subproblem represents the optimal equity infusion problem when a given subset of core banks is guaranteed to be collectively solvent. As we will see, each sub-problem will be decoupled from the network fixed point and is a simple convex optimization problem.

More formally, we define, for a subset of core banks $S \subseteq \mathcal{C}$, the subset of admissible intervention strategies in which we allow only the banks in $S$ to receive government intervention

$$
\forall S \subseteq \mathcal{C}, \mathcal{A}_{M}^{S}:=\left\{\xi \in \mathcal{A}_{M}, \forall i \in S, R_{i}(\xi) \geq 1, \forall i \in[n] \backslash S, \xi_{i}=0\right\}
$$

The constraint $R_{i}(\xi) \geq 1$ is set since, by Proposition 6, the government does not invest in a bank that is insolvent in equilibrium.

We define the sub-problem

$$
\mathcal{P}_{M}^{S}:=\underset{\xi \in \mathcal{A}_{M}^{S}}{\operatorname{Minimize}} L(\xi)
$$

and let $L^{*}(S)$ the value of its solution. The next sub-section is dedicated to showing that $\mathcal{P}_{M}^{S}$ is a convex optimization problem and thus it has a unique solution, see Corollary 13 . Moreover we will show that the solution to the sub-problem is decoupled from the network fixed point.

We can now state our first main result.

Theorem 8. Assume the illiquid asset has a fire-sale price $p<1$ and assume that there exists a bank $i$ fundamentally insolvent or illiquid, i.e., $r_{i}<1$ or $\gamma_{i}<s_{i} g\left(r_{i}\right)$. Let $S^{*}$ the 
minimizer over $2^{\mathcal{C}}$ of $L^{*}(S)$. Let $\xi^{*}$ the solution to $\mathcal{P}_{M}^{S^{*}}$. Then $\xi^{*}$ is the solution to the optimal equity infusion problem $\mathcal{P}_{M}$.

Proof. Thanks to Proposition 6, we can write

$$
\begin{aligned}
\mathcal{P}_{M} & =\underset{\xi \in \mathcal{A}_{M}}{\operatorname{Minimize}} L(\xi) \\
& =\underset{S \subseteq \mathcal{C}, \xi \in \mathcal{A}_{M}^{S}}{\operatorname{Minimize}} L(\xi) \\
& =\underset{S \subseteq \mathcal{C}}{\operatorname{Minimize}} L^{*}(S) .
\end{aligned}
$$

The solution has a combinatorial aspect, requiring to assess for each set $S \subseteq \mathcal{C}$ of eligible banks the solution to the sub-problem $\mathcal{P}_{M}^{S}$. In other words, we need to assess, for each set $S \subseteq \mathcal{C}$ the cost of guaranteeing all banks in that set to be solvent. The solution is tractable when the number of banks that are eligible for infusions is sufficiently small. In particular, it may be suboptimal to guarantee all core banks to be solvent. The decision however cannot be simply stated in terms of the balance sheets of these banks and requires to solve the convex combinatorial optimization problem above. In particular the complete network observation is required.

Optimal equity infusion sub-problem when all banks in a given set is guaranteed to be solvent. In this section, we show that the sub-problem $\mathcal{P}_{M}^{S}$ is a convex optimization problem. Fix now an intervention strategy $\xi \in \mathcal{A}_{M}^{S}$.

Remark 9. For $i \in[n] \backslash S$, the recovery rate $R_{i}(\xi)$ can be computed as a fixed point of the following function

$$
\phi(x, S)_{i, i \in[n] \backslash S}:=\frac{y_{i}-\delta\left(x_{i}, s_{i}, \gamma_{i}, y_{i}\right)+\sum_{j \in S} \ell_{j} \pi_{j i}+\sum_{j \notin S} \ell_{j} \pi_{j i}\left(x_{j} \wedge 1\right)}{\ell_{i}+s_{i}} .
$$

The above function is a modified version of the function $\Phi$ in which all banks in the set of banks $S$ are guaranteed to be solvent, i.e., the asset-to-debt ratio is larger than 1 for any bank belonging to the set $S$. We denote its largest fixed point by $\left(R_{i}^{S}\right)_{i \in[n] \backslash S}$.

In other words, we have determined the asset-to-debt ratios for the banks in $[n] \backslash S$, when all banks in the set of banks $S$ are guaranteed to be solvent. This is the only point in the sub-problem when we need to compute a network fixed point, but note that this fixed point does not depend on the equity infusions, since no bank in $[n] \backslash S$ receives equity infusions. This means that the asset-to-debt ratios for the banks in $[n] \backslash S$ are constant on 
the set of intervention strategies $\mathcal{A}_{M}^{S}$, i.e., for all $i \in[n] \backslash S$ we have

$$
R_{i}(\xi)=R_{i}^{S}, \forall \xi \in \mathcal{A}_{M}^{S}
$$

We now note that for all $i \in S$ and for all $\xi \in \mathcal{A}_{M}^{S}$ the asset-to-debt ratio of bank $i$ is given as the fixed point of the real-valued function $f^{S}\left(\cdot, \xi_{i}\right): \mathbb{R}^{+} \rightarrow \mathbb{R}^{+}$,

$$
f^{S}\left(x, \xi_{i}\right):=\frac{y_{i}-\delta\left(x, s_{i}, \gamma_{i}+\xi_{i}, y_{i}\right)+\gamma_{i}+\xi_{i}+\sum_{j \in S} \ell_{j} \pi_{j i}+\sum_{j \notin S} \ell_{j} \pi_{j i}\left(R_{j}^{S} \wedge 1\right)}{\ell_{i}+s_{i}} .
$$

We let the minimal government infusion that makes bank $i \in S$ solvent

$$
\underline{\xi}_{i}^{S}:=\inf \left\{\xi_{i} \mid f^{S}\left(1, \xi_{i}\right) \geq 1\right\}
$$

We have the following immediate result about the set of admissible strategies when we restrict intervention to the subset $S \subseteq \mathcal{C}$ of core banks.

Proposition 10. Fix $i \in S$. The set of admissible strategies in which we allow only the banks in $S$ to receive government intervention is given by

$$
\mathcal{A}_{M}^{S}= \begin{cases}\emptyset & \text { if } \sum_{i \in S} \underline{\xi}_{i}^{S} \geq M \\ \left\{\xi \in \mathbb{R}^{n} \mid \forall i \in[n] \backslash S, \xi_{i}=0, \forall i \in S, \xi_{i} \geq \underline{\xi}_{i}^{S}, \sum_{i \in S} \xi_{i} \leq M\right\} & \text { otherwise. }\end{cases}
$$

If $\mathcal{A}_{M}^{S} \neq \emptyset$, then for all $\xi \in \mathcal{A}_{M}^{S}$ there is a unique fixed point larger than 1 for the map $f^{S}\left(\cdot, \xi_{i}\right)$. We denote this fixed point by $R_{i}^{S}\left(\xi_{i}\right)$ and we have $R_{i}(\xi)=R_{i}^{S}\left(\xi_{i}\right)$.

Proof. Since $g$ is decreasing in $\xi_{i}$, we have that $\forall x, \xi_{i} \rightarrow f^{S}\left(x, \xi_{i}\right)$ is increasing with $\lim _{\xi_{i} \rightarrow \infty} f^{S}\left(x, \xi_{i}\right)=\infty$. For $\xi_{i}$ sufficiently large, $f^{S}\left(1, \xi_{i}\right) \geq 1$.

We now fix $\xi \in \mathcal{A}_{M}^{S} \neq \emptyset$. We let

$$
I_{i}^{S}\left(\xi_{i}\right):=\left(\frac{1}{p}-1\right) \mathbb{1}_{0<s_{i} g\left(R_{i}^{S}\left(\xi_{i}\right)\right)-\gamma_{i}-\xi_{i}<p y_{i}} .
$$

This quantity captures the ratio between the fundamental value and the fire-sale price for banks forced to liquidate. We have

$$
\frac{\partial f^{S}\left(x, \xi_{i}\right)}{\partial x}=-\frac{\partial \delta}{\partial x} \delta\left(x, s_{i}, \gamma_{i}+\xi_{i}, y_{i}\right) /\left(\ell_{i}+s_{i}\right)=-s_{i} g^{\prime}(x) I_{i}^{S}\left(\xi_{i}\right) /\left(\ell_{i}+s_{i}\right) \geq 0
$$

From the Assumption 1 (iii) it also follows that

$$
\frac{\partial f^{S}\left(x, \xi_{i}\right)}{\partial x} \leq s_{i} /\left(\ell_{i}+s_{i}\right)<1
$$


We also have

$$
\frac{\partial^{2} f^{S}\left(x, \xi_{i}\right)}{\partial x^{2}}=-\frac{\partial \delta}{\partial x} \delta\left(x, s_{i}, \gamma_{i}+\xi_{i}, y_{i}\right) \leq 0,
$$

where the inequality holds thanks to the convexity of the function $g$ (Assumption 1 (ii)).

The function $f^{S}\left(\cdot, \xi_{i}\right)$ is thus continuous, increasing, concave and is bounded. Its first derivative is bounded from above by 1 . It follows that $f^{S}\left(\cdot, \xi_{i}\right)$ has either no fixed point or one fixed point, depending on whether $f^{S}\left(1, \xi_{i}\right)$ is smaller or greater than 1 . Since $f^{S}\left(1, \xi_{i}\right)>1$, by the assumption that $\xi \in \mathcal{A}_{M}^{S} \neq \emptyset$, there is a unique fixed point.

The previous proposition shows in particular that for $i \in S$ and $\xi \in \mathcal{A}_{M}^{S}, R_{i}(\xi)$ depends on $\xi$ only through $\xi_{i}$. The intuition is simple. No bank outside the set $S$ receives equity infusions and we are guaranteed that banks in $S$ pay their debts in full. Therefore the equilibrium payments of the banks outside the set $S$ do not depend on the actual amount of the equity infusions. For any bank in the set $S$ its debt-to-asset ratio depends only on its own equity infusion.

For $i \in S$, the dead-weight losses are given by

$$
\Delta_{i}(\xi)=\Delta_{i}^{S}\left(\xi_{i}\right):=\delta\left(R_{i}^{S}\left(\xi_{i}\right), s_{i}, \gamma_{i}+\xi_{i}, y_{i}\right)
$$

From Eq. 12 and noting that $R_{i}^{S}\left(\xi_{i}\right)>1$ for $i \in S$, the total loss writes

$$
\begin{aligned}
L(\xi)= & \sum_{i \in S}\left(\Delta_{i}^{S}\left(\xi_{i}\right)+\xi_{i} d+\left(\left(R_{i}^{S}\left(\xi_{i}\right)-1\right)\left(\ell_{i}+s_{i}\right)-\xi_{i}(1+d)\right)^{-}\right) \\
& +\sum_{i \in[n] \backslash S} \Delta_{i}^{S}+\sum_{i \in[n] \backslash S}\left(R_{i}^{S}-1\right)^{-}\left(s_{i}+\ell_{i}\right) .
\end{aligned}
$$

We can immediately attribute the loss to each bank $i \in S$ (the first summation above) and respectively to the set of banks $[n] \backslash S$ (the last two summations above). Remark in particular that the loss attributed to the banks in $[n] \backslash S$ is constant over $\mathcal{A}_{M}^{S}$.

Formally, for a bank $i \in S$, we define the contribution of bank $i$ to the loss in system fundamental value as

$$
L_{i}^{S}\left(\xi_{i}\right):=\Delta_{i}^{S}\left(\xi_{i}\right)+\xi_{i} d+\left(\left(R_{i}^{S}\left(\xi_{i}\right)-1\right)\left(\ell_{i}+s_{i}\right)-\xi_{i}(1+d)\right)^{-} .
$$

We have the following lemma.

Lemma 11. The map $\xi_{i} \rightarrow \Delta_{i}^{S}\left(\xi_{i}\right)+\xi_{i} d$ is convex over $\mathcal{A}_{M}^{S}$. The map $\xi_{i} \rightarrow L_{i}^{S}\left(\xi_{i}\right)$ is convex over $\mathcal{A}_{M}^{S}$.

The proof of this lemma is given in Appendix A 
Remark 12. If $\frac{d \Delta_{i}^{S}\left(\underline{\xi}_{i}\right)}{d \xi_{i}}+d \geq 0$ then $\xi_{i}=\underline{\xi}_{i}$, i.e., the equity infusion is equal to to the minimum equity infusion for which the bank is solvent. The gradient $\frac{d L(\underline{\xi})}{d \xi_{i}} \leq 0$ at the minimum equity infusion is decreasing with the ratio of unstable short term debt to total debt $\frac{s_{i}}{s_{i}+l_{i}}$ whenever $g^{\prime}(1)<0$. This shows that banks with larger fraction of unstable short term debt receive equity infusions in priority, in order to minimize dead-weight losses.

We obtain as an immediate consequence the following result, key in proving Theorem 8 .

Corollary 13. Let $S \subseteq \mathcal{C}$. Consider the problem

$$
\begin{array}{rlrl}
\mathcal{P}_{M}^{S} & =\underset{\xi \in \mathcal{A}_{M}^{S}}{\operatorname{Minimize}} & L(\xi) & \\
& =\underset{\xi \in \mathcal{A}_{M}^{S}}{\operatorname{Minimize}} & \sum_{i \in S} L_{i}^{S}(\xi)+\sum_{i \in[n] \backslash S} \Delta_{i}^{S}+\sum_{i \in[n] \backslash S}\left(R_{i}^{S}-1\right)^{-}\left(s_{i}+\ell_{i}\right),
\end{array}
$$

where $L\left(\xi_{i}\right)$ is defined in $E q$. (20) and $L_{i}^{S}(\xi)$ is defined in Eq. (21). It has a unique solution whose value is denoted $L^{*}(S)$.

Using Lemma 11, the problem $\mathcal{P}_{M}^{S}$ is a convex optimization problem and thus has a unique solution.

Note that this problem is decoupled from the network fixed point.

The case when all core banks is guaranteed to be solvent. Of particular interest the case when government equity infusions guarantees that all core banks are solvent. We set now $S=\mathcal{C}$ and use the definitions in the previous paragraph, with $S=\mathcal{C}$.

We are intersted in the solution to the problem $\mathcal{P}_{M}^{\mathcal{C}}$. We assume that the budget is sufficiently large such that a nontrivial solution to $\mathcal{P}_{M}^{\mathcal{C}}$ exists, i.e., $\sum_{i \in \mathcal{C}} \underline{\xi}_{i}^{\mathcal{C}} \leq M$.

We denote by $\xi_{i}^{*}$ the unconstrained minimum of the convex function $L_{i}^{\mathcal{C}}\left(\xi_{i}\right)$ on the interval $\left[\underline{\xi}_{i}^{\mathcal{C}}, \infty\right)$. Thanks to Eq. 23 and 24 it is given by

$$
\xi_{i}^{*}= \begin{cases}\frac{1+I_{i}^{\mathcal{C}}\left(\xi_{i}\right)}{1+\frac{s_{i}}{\ell_{i}+s_{i}} g^{\prime}\left(R_{i}^{\mathcal{C}}\left(\xi_{i}\right)\right) I_{i}^{\mathcal{C}}\left(\xi_{i}\right)}=1+d & \text { if } \frac{1+I_{i}^{\mathcal{C}}\left(\underline{\mathcal{F}}_{i}^{\mathcal{C}}\right)}{1+\frac{s_{i}}{\ell_{i}+s_{i}} g^{\prime}(1) I_{i}^{\mathcal{C}}\left(\underline{\xi}_{i}^{\mathcal{C}}\right)} \leq 1+d \\ \underline{\xi}_{i}^{\mathcal{C}} & \text { otherwise }\end{cases}
$$

Remark 14. Note that the optimal amount of equity infusions increases in the ratio of short to total debt $\frac{s_{i}}{\ell_{i}+s_{i}}$, the short term creditors outflow rate $g^{\prime}\left(R_{i}^{\mathcal{C}}\left(\xi_{i}\right)\right)$ and $I_{i}^{\mathcal{C}}\left(\xi_{i}^{\mathcal{C}}\right)$ that captures the ratio between the fundamental value and the fire-sale price for banks forced to liquidate.

Remark 15. Note that $\sum_{i \in \mathcal{C}} \xi_{i}^{*}$ is the value of the government infusion that minimizes the loss in the financial system under the constraint that all core banks are solvent. In 
particular, if $M \geq \sum_{i \in \mathcal{C}} \xi_{i}^{*}$ then it immediately follows that the budget constraint is not saturated.

Otherwise it is given by the dual problem

$$
\underset{\lambda \in \mathbb{R}, \xi_{i} \geq \underline{\xi}_{i}^{\mathcal{C}}}{\operatorname{Minimize}} \sum_{i} L_{i}^{\mathcal{C}}\left(\xi_{i}\right)+\lambda\left(\sum \xi_{i}-M\right)
$$

and the solution to the problem $\mathcal{P}_{M}^{\mathcal{C}}$ is given by

$$
\xi_{i}^{*}(\lambda):= \begin{cases}\frac{1+I_{i}^{\mathcal{C}}\left(\xi_{i}\right)}{1+\frac{s_{i}}{\ell_{i}+s_{i}} g^{\prime}\left(R_{i}^{\mathcal{C}}\left(\xi_{i}\right)\right) I_{i}^{\mathcal{C}}\left(\xi_{i}\right)}=1+d+\lambda & \text { if } \frac{1+I_{i}^{\mathcal{C}}\left(\underline{\mathcal{F}}_{i}^{\mathcal{C}}\right)}{1+\frac{s_{i}}{\ell_{i}+s_{i}} g^{\prime}(1) I_{i}^{\mathcal{C}}\left(\underline{\xi}_{i}^{\mathcal{C}}\right)} \leq 1+d, \\ \underline{\xi}_{i} & \text { otherwise }\end{cases}
$$

with the Lagrange multiplier $\lambda$ obtained from the equation

$$
\sum_{i \in \mathcal{C}} \xi_{i}^{*}(\lambda)=M
$$

Is it optimal for the banks to receive the government equity infusion? We now give the second main result of the paper. This states that, whatever the set of banks that are guaranteed not to fail, the government equity infusion is such that the capital of all banks increases after intervention and after the transfer of the dividend to the government. This means that banks are better off by receiving the equity infusion and paying the dividend than not joining the equity infusion program.

Theorem 16. Fix a subset $S \subseteq \mathcal{C}$ of banks that are all guaranteed to be solvent. Let $\xi^{*}$ be the solution to the problem $\mathcal{P}_{M}^{S}$. Then, for all $i \in[n]$ we have $C_{i}\left(\xi^{*}\right) \geq C_{i}(0)$.

The proof is given in Appendix B.

\subsection{Numerical experiments}

In the numerical examples we illustrate our theoretical findings on a simulated network generated similarly as in Amini et al. (2013a).

Figure 1 illustrates the idea behind our solution to the optimal equity infusion problem. Each point represents a set of banks that are guaranteed to be collectively solvent (in total $2^{|\mathcal{C}|}$ such sets) and the value of the solution for the corresponding sub-problem. For each set we plot the total loss in the system versus the total equity infusion (when the respective set is guaranteed to be solvent).

We observe that the budget constraint is not saturated at the optimal solution, see Remark 15. This result suggests that injecting equity beyond a certain limit would not serve to mitigate systemic risk. 


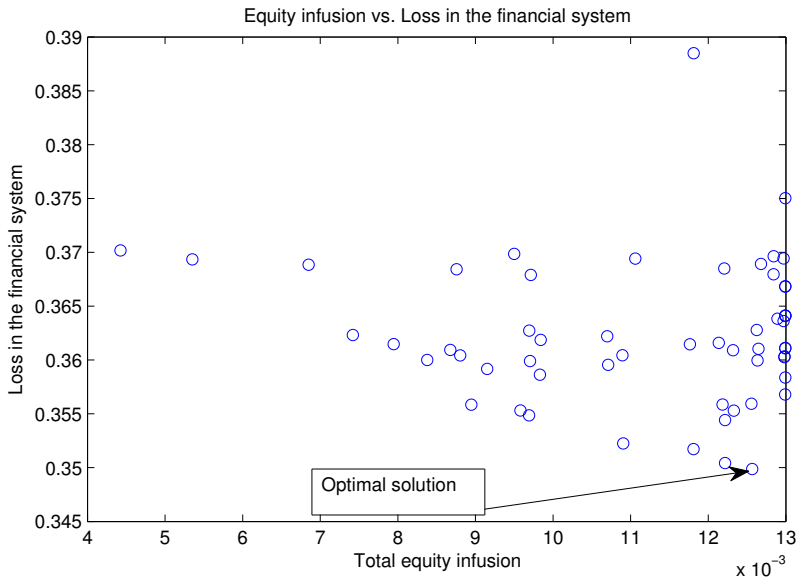

Figure 1: Total loss in the system vs. total equity infusion. Each point represents a set of banks that are guaranteed to be collectively solvent. All quantities are expressed as a percentage of the fundamental net worth of the financial system.

We next plot in Figure 2 the optimal value of the problem $\mathcal{P}_{M}$ for varying $M$. We observe that the loss in the system is significantly mitigated as we increase $M$ and that this effect decreases with the maximum budget $M$.

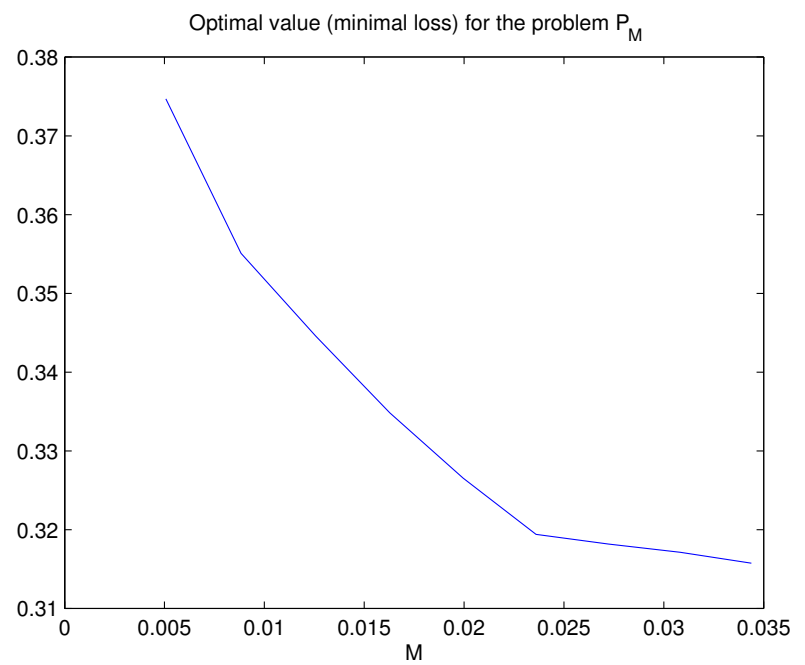

Figure 2: Optimal value for the problem $\mathcal{P}_{M}$ for varying $M$.

We now fix $M$ and vary the liquidation price $p$ (we could vary alternatively the parameters for the creditor outflow schedule so as to increase the outflow). We plot, for each value of the liquidation price $p$, the optimal equity infusion and the value of the solution. The results are shown in Figure 3 .

The numerical results corroborate the theoretical results, namely that in absence of dead- 

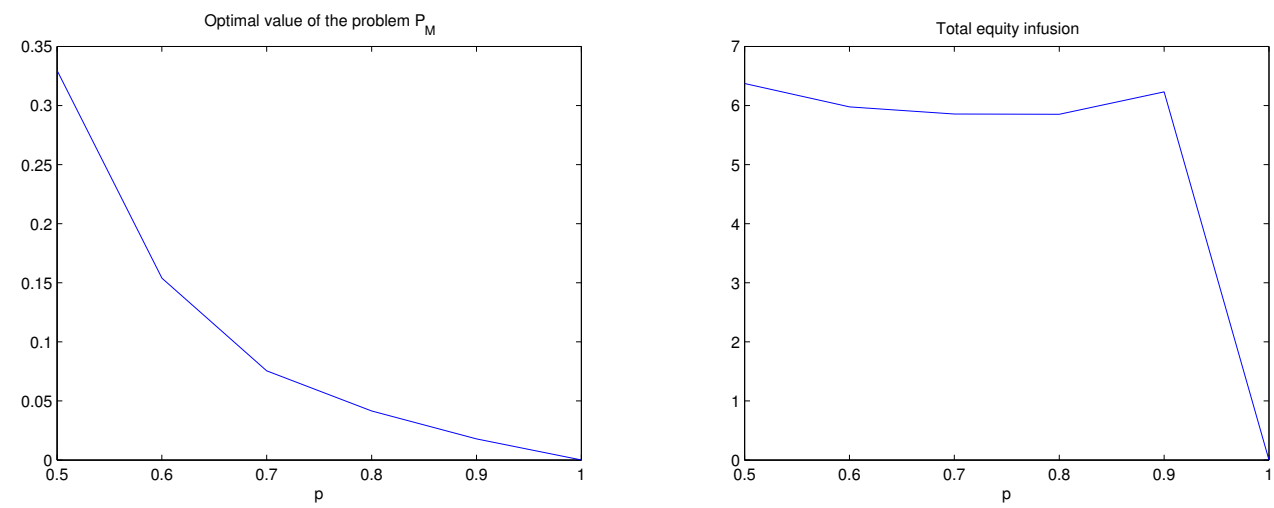

Figure 3: Optimal value and optimal total equity infusion for the problem $\mathcal{P}_{M}$ for varying $p$. All quantities are expressed as a percentage of the fundamental value of the financial system, as

weight losses, i.e., $p=1$, there is no intervention, see Proposition 7 . As the liquidation price decreases, the amount of equity infusions increases.

\section{Conclusions}

We have written an optimization program for a government with constrained budget seeking to maximize the net worth of a financial system comprising of banks and their outside creditors. The government makes preferred equity infusions in the form of cash. When banks are prone to bank runs and invest in an illiquid asset, there exists a non-trivial solution to this problem. In our setting, a non trivial solution to the problem implies in particular that it is preferable for the government to invest in the banks' equity than to invest directly in the economy (for example by directly funding projects).

We find that all banks are better off by participating in the program. The government may find it optimal to invest in a strict subset of the core banks. The decision however cannot be simply stated in terms of the balance sheets of these banks and requires to solve a convex optimization problem for every subset of banks, to which we restrict infusions and which are all guaranteed solvent. In particular the complete network observation is required.

We offer a methodology to test the theory that the rationale behind the large equity infusions in 2008 was to avoid runs by short term creditors, and implicitly to minimize the dead weight losses induced by creditor outflows. Given the precise interbank network and balance sheet composition for each bank, one can compute the optimal equity infusions in each of the core banks (which may be zero for some core banks, i.e, no equity infusions).

There exist, of course, other kinds of interventions for supporting liquidity which do 
not take the form of equity infusions, but that of loans or credit guarantees. These are important topics for future research, which can be studied with methods similar to the current paper. Equity infusions in 2008, on the other hand, constituted the largest ever U.S. government intervention in the financial sector, and our results are intended to be used as tools for the decision process in this type of interventions.

\section{A Proof of Lemma 11}

Proof. From the definition of $R_{i}^{S}\left(\xi_{i}\right)$ as the unique fixed point in the interval $[1, \infty)$ in Eq. (16) we have

$$
\begin{aligned}
\left(\ell_{i}+s_{i}\right) \frac{d R_{i}^{S}\left(\xi_{i}\right)}{d \xi_{i}}= & -\frac{\partial \delta}{\partial x}\left(R_{i}^{S}\left(\xi_{i}\right), s_{i}, \gamma_{i}+\xi_{i}, y_{i}\right) \frac{d R_{i}^{S}\left(\xi_{i}\right)}{d \xi_{i}}-\frac{\partial \delta}{\partial \gamma}\left(R_{i}^{S}\left(\xi_{i}\right), s_{i}, \gamma_{i}+\xi_{i}, y_{i}\right)+1 \\
\left(\ell_{i}+s_{i}\right) \frac{d^{2} R_{i}^{S}\left(\xi_{i}\right)}{\left(d \xi_{i}\right)^{2}}= & -\frac{\partial \delta}{\partial x}\left(R_{i}^{S}\left(\xi_{i}\right), s_{i}, \gamma_{i}+\xi_{i}, y_{i}\right) \frac{d^{2} R_{i}^{S}\left(\xi_{i}\right)}{\left(d \xi_{i}\right)^{2}} \\
& -\frac{\partial^{2} \delta}{\partial x^{2}}\left(R_{i}^{S}\left(\xi_{i}\right), s_{i}, \gamma_{i}+\xi_{i}, y_{i}\right)\left(\frac{d R_{i}^{S}\left(\xi_{i}\right)}{d \xi_{i}}\right)^{2} \\
& -2 \frac{\partial^{2} \delta}{\partial x \partial \gamma}\left(R_{i}^{S}\left(\xi_{i}\right), s_{i}, \gamma_{i}+\xi_{i}, y_{i}\right) \frac{d R_{i}^{S}\left(\xi_{i}\right)}{d \xi_{i}} \\
& -\frac{\partial^{2} \delta}{\partial \gamma^{2}}\left(R_{i}^{S}\left(\xi_{i}\right), s_{i}, \gamma_{i}+\xi_{i}, y_{i}\right) .
\end{aligned}
$$

We let

$$
I_{i}^{S}\left(\xi_{i}\right):=\left(\frac{1}{p}-1\right) \mathbb{1}_{0<s_{i} g\left(R_{i}^{S}\left(\xi_{i}\right)\right)-\gamma_{i}-\xi_{i}<p y_{i}} .
$$

We obtain, using Assumption 1 (iii), that

$$
\begin{aligned}
\frac{d R_{i}^{S}\left(\xi_{i}\right)}{d \xi_{i}} & =\frac{1-\frac{\partial \delta}{\partial \gamma}\left(R_{i}^{S}\left(\xi_{i}\right), s_{i}, \gamma_{i}+\xi_{i}, y_{i}\right)}{\ell_{i}+s_{i}+\frac{\partial \delta}{\partial x}\left(R_{i}^{S}\left(\xi_{i}\right), s_{i}, \gamma_{i}+\xi_{i}, y_{i}\right)} \\
& =\frac{1+I_{i}^{S}\left(\xi_{i}\right)}{\ell_{i}+s_{i}+s_{i} g^{\prime}\left(R_{i}^{S}\left(\xi_{i}\right)\right) I_{i}^{S}\left(\xi_{i}\right)} \\
& \geq 0 \\
\frac{d^{2} R_{i}^{S}\left(\xi_{i}\right)}{\left(d \xi_{i}\right)^{2}} & =\frac{-\frac{\partial^{2} \delta}{\partial x^{2}}\left(R_{i}^{S}\left(\xi_{i}\right), s_{i}, \gamma_{i}+\xi_{i}, y_{i}\right)\left(\frac{d R_{i}^{S}\left(\xi_{i}\right)}{d \xi_{i}}\right)^{2}}{\ell_{i}+s_{i}+\frac{\partial \delta}{\partial x}\left(R_{i}^{S}\left(\xi_{i}\right), s_{i}, \gamma_{i}+\xi_{i}, y_{i}\right)} \\
& =\frac{-s_{i} g^{\prime \prime}\left(R_{i}^{S}\left(\xi_{i}\right)\right) I_{i}^{S}\left(\xi_{i}\right)\left(\frac{d R_{i}^{S}\left(\xi_{i}\right)}{d \xi_{i}}\right)^{2}}{\ell_{i}+s_{i}+s_{i} g^{\prime}\left(R_{i}^{S}\left(\xi_{i}\right)\right) I_{i}^{S}\left(\xi_{i}\right)} \\
& \leq 0
\end{aligned}
$$


It then immediately follows

$$
\begin{aligned}
\frac{d \Delta_{i}^{S}\left(\xi_{i}\right)}{d \xi_{i}} & =1-\left(\ell_{i}+s_{i}\right) \frac{d R_{i}^{S}\left(\xi_{i}\right)}{d \xi_{i}} \\
& =1-\frac{1+I_{i}^{S}\left(\xi_{i}\right)}{1+\frac{s_{i}}{\ell_{i}+s_{i}} g^{\prime}\left(R_{i}^{S}\left(\xi_{i}\right)\right) I_{i}^{S}\left(\xi_{i}\right)} \\
& =\frac{I_{i}^{S}\left(\xi_{i}\right)\left(\frac{s_{i}}{\ell_{i}+s_{i}} g^{\prime}\left(R_{i}^{S}\left(\xi_{i}\right)\right)-1\right)}{1+\frac{s_{i}}{\ell_{i}+s_{i}} g^{\prime}\left(R_{i}^{S}\left(\xi_{i}\right)\right) I_{i}^{S}\left(\xi_{i}\right)} \\
& \leq 0 ; \\
\frac{d^{2} \Delta_{i}^{S}\left(\xi_{i}\right)}{\left(d \xi_{i}\right)^{2}} & =-\left(\ell_{i}+s_{i}\right) \frac{d^{2} R_{i}^{S}\left(\xi_{i}\right)}{\left(d \xi_{i}\right)^{2}} \geq 0 .
\end{aligned}
$$

We have obtained the first part of the lemma, namely that the map

$$
\xi_{i} \rightarrow \Delta_{i}^{S}\left(\xi_{i}\right)+\xi_{i} d
$$

is convex. We now show the second part of the lemma. We have

$$
\begin{aligned}
\frac{d L_{i}^{S}(\xi)}{d \xi_{i}} & =d+\frac{d \Delta_{i}^{S}\left(\xi_{i}\right)}{d \xi_{i}}+\mathbb{1}_{\left(R_{i}^{S}\left(\xi_{i}\right)-1\right)\left(\ell_{i}+s_{i}\right)<\xi_{i}(1+d)}\left(-\left(\ell_{i}+s_{i}\right) \frac{d R_{i}^{S}\left(\xi_{i}\right)}{d \xi_{i}}+1+d\right) \\
& =d+\frac{d \Delta_{i}^{S}\left(\xi_{i}\right)}{d \xi_{i}}+\mathbb{1}_{\left(R_{i}^{S}\left(\xi_{i}\right)-1\right)\left(\ell_{i}+s_{i}\right)<\xi_{i}(1+d)}\left(\frac{d \Delta_{i}^{S}\left(\xi_{i}\right)}{d \xi_{i}}+d\right) \\
& =\left(\frac{d \Delta_{i}^{S}\left(\xi_{i}\right)}{d \xi_{i}}+d\right)\left(1+\mathbb{1}_{\left(R_{i}^{S}\left(\xi_{i}\right)-1\right)\left(\ell_{i}+s_{i}\right)<\xi_{i}(1+d)}\right) . \\
\frac{d^{2} L_{i}^{S}(\xi)}{\left(d \xi_{i}\right)^{2}} & =\frac{d^{2} \Delta_{i}^{S}\left(\xi_{i}\right)}{\left(d \xi_{i}\right)^{2}}\left(1+\mathbb{1}_{\left(R_{i}^{S}\left(\xi_{i}\right)-1\right)\left(\ell_{i}+s_{i}\right)<\xi_{i}(1+d)}\right) \\
& \geq 0 .
\end{aligned}
$$

In the second line above we have used Eq. (23). In the last inequality we have used the first part of the lemma. This completes the proof of the lemma.

\section{B Proof of Theorem 16}

Proof. In light of Eq. (7), we can write the condition $C_{i}(\xi) \geq C_{i}(0)$ as

$$
\Delta_{i}\left(\xi^{*}\right)+\xi_{i}^{*} d \leq \Delta_{i}(0)+\sum_{j \in[n]} \ell_{j} \pi_{j i}\left(R_{j}\left(\xi^{*}\right) \wedge 1-R_{j}(0) \wedge 1\right)
$$


which becomes a simple constraint on $\xi_{i}^{*}$ as follows

$$
\begin{aligned}
& \forall i \in S, \Delta_{i}^{S}\left(\xi_{i}^{*}\right)+\xi_{i}^{*} d \leq \\
& \quad \Delta_{i}(0)+\sum_{j \in S} \ell_{j} \pi_{j i}\left(1-R_{j}(0) \wedge 1\right)+\sum_{j \in[n] \backslash S} \ell_{j} \pi_{j i}\left(R_{j}^{S} \wedge 1-R_{j}(0) \wedge 1\right) .
\end{aligned}
$$

Suppose now by way of contradiction that there exists $i$ such that $C_{i}(\xi)<C_{i}(0)$, i.e.,

$$
\Delta_{i}\left(\xi^{*}\right)+\xi_{i}^{*} d>\Delta_{i}(0)+\sum_{j \in[n]} \ell_{j} \pi_{j i}\left(R_{j}\left(\xi^{*}\right) \wedge 1-R_{j}(0) \wedge 1\right)
$$

This inequality cannot hold for $i \in[n] \backslash S$, who receive no infusion but have indirect gains from equity infusions in their debtors.

Suppose that above inequality holds for $i \in S$. Thanks to Lemma 11, the map $\xi_{i} \rightarrow$ $\Delta_{i}\left(\xi_{i}\right)+\xi_{i} d$ is convex on $\mathcal{A}_{M}^{S}$. Since $\Delta_{i}\left(\xi^{*}\right)+\xi^{*} \geq \Delta_{i}(0)$, it follows that the map attains its minimum for a $\xi_{i}^{\prime}<\xi_{i}^{*}$. But since $\xi_{i}^{*}$ is a solution to $\mathcal{P}_{M}^{S}$, it must be that

$$
\left(\left(R_{i}^{S}\left(\xi_{i}^{\prime}\right)-1\right)\left(\ell_{i}+s_{i}\right)-\xi_{i}^{\prime}(1+d)\right)^{-} \geq\left(\left(R_{i}^{S}\left(\xi_{i}^{*}\right)-1\right)\left(\ell_{i}+s_{i}\right)-\xi_{i}^{*}(1+d)\right)^{-} .
$$

This is equivalent to $\left(R_{i}^{S}\left(\xi_{i}^{\prime}\right)-1\right)\left(\ell_{i}+s_{i}\right)-\xi_{i}^{\prime}(1+d) \leq 0$ and

$$
\left(R_{i}^{S}\left(\xi_{i}^{\prime}\right)-1\right)\left(\ell_{i}+s_{i}\right)-\xi_{i}^{\prime}(1+d) \leq\left(R_{i}^{S}\left(\xi_{i}^{*}\right)-1\right)\left(\ell_{i}+s_{i}\right)+\xi_{i}^{*}(1+d)
$$

i.e. $\Delta_{i}^{S}\left(\xi_{i}^{\prime}\right)+\xi_{i}^{\prime} d \geq \Delta_{i}^{S}\left(\xi_{i}^{*}\right)-\xi_{i}^{*} d$. If $\xi_{i}^{\prime}$ is a strict minimum, then we directly obtain a contradiction. If with $\xi_{i}^{\prime}$ is not a strict minimum then we have a contradiction with Assumption 3 .

Acknowledgement We thank Hamed Amini for valuable discussions.

\section{References}

Amini, H., Cont, R., and Minca, A. (2013a). Resilience to contagion in financial networks. Mathematical Finance.

Amini, H., Filipovic, D., and Minca, A. (2013b). Systemic risk with central counterparty clearing. Swiss Finance Institute Research Paper No. 13-34. Available at SSRN: http://ssrn. com// abstract $=22^{275376}$.

Amini, H., Minca, A., and Sulem, A. (2012). Optimal equity infusions in financial networks. Available at SSRN: http://dx. doi.org/10.2139/ssrn.2128476.

Bayazitova, D. and Shivdasani, A. (2012). Assessing TARP. Review of Financial Studies, 25(2):377407. 
Blanchet, J. and Shi, Y. (2012). Stochastic Risk Networks: Modeling, Analysis and Efficient Monte Carlo. Preprint available at http://ssrn.com/paper $=2012987$.

Chen, C., Iyengar, G., and Moallemi, C. (2012). An axiomatic approach to systemic risk. To appear in Management Science.

Cifuentes, R., Ferrucci, G., and Shin, H. (2005). Liquidity risk and contagion. Journal of the European Economic Association, 3:556-566.

Cont, R., Moussa, A., and Santos, E. B. (2012). Network structure and systemic risk in banking systems. In Fouque, J.-P. and Langsam, J., editors, Handbook of systemic risk.

Diamond, D. W. and Rajan, R. G. (2011). Fear of fire sales, illiquidity seeking, and credit freezes. The Quarterly Journal of Economics, 126(2):557-591.

Eisenberg, L. and Noe, T. H. (2001). Systemic Risk in Financial Systems. Management Science, $47(2): 236-249$.

Giesecke, K. and Kim, B. (2011). Systemic risk: What defaults are telling us. Management Science, 57(8):1387-1405.

Glasserman, P. and Wang, Z. (2011). Valuing the treasury's capital assistance program. Management Science, 57(7):1195-1211.

Gorton, G. and Metrick, A. (2012). Securitized banking and the run on repo. Journal of Financial Economics, 104(3):425 - 451.

He, Z. and Xiong, W. (2012). Rollover risk and credit risk. Journal of Finance, 67(2):391-430.

Krishenik, A., Minca, A., and Wissel, J. (2012). When do creditors with heterogeneous beliefs agree to run?

Landler, M. and Dash, E. (2008). Drama behind a $\$ 250$ billion banking deal. The New York Times.

Lehar, A. (2005). Measuring systemic risk: A risk management approach. Journal of Banking and Finance, 29(10):2577-2603.

Lütkebohmert, E., Liang, G., and Xiao, Y. (2012). A multi-period bank run model for liquidity risk. Forthcoming in Review of Finance.

Morris, S. and Shin, H. S. (2009). Illiquidity component of credit risk. Working paper.

Philippon, T. and Schnabl, P. (2009). Efficient recapitalization. Forthcoming in Journal of Finance.

Philippon, T. and Skreta, V. (2010). Optimal interventions in markets with adverse selection. Working Paper 15785, National Bureau of Economic Research.

Rogers, L. and Veraart, L. (2012). Failure and rescue in an interbank network. Forthcoming in Management Science.

Swagel, P. (2009). The financial crisis: An inside view. Brookings Papers on Economic Activity, 2009(1):1-63.

Veronesi, P. and Zingales, L. (2010). Paulson's gift. Journal of Financial Economics, 97(3):339 368. 